\section{A doença mental feminina em Porto Alegre, Rio Grande do Sul, Brasil (1870-1910)}

\author{
Mental illness in women in Porto Alegre, \\ Rio Grande do Sul, Brazil (1870-1910)
}

\footnotetext{
1 Amigos da Memória do Hospital São Pedro, Porto Alegre, Brasil.

2 Oficina de Criatividade Nise da Silveira, Hospital Psiquiátrico São Pedro, Porto Alegre, Brasil. 3 Universidade Federal do Rio Grande do Sul. Porto Alegre, Brasil. ${ }^{4}$ Faculdades de Taquara, Taquara, Brasil.

Correspondência C. T. D. V. Vasconcellos Amigos da Memória do Hospital São Pedro. Av. Protasio Alves 770 apto. 33, Porto Alegre, RS 90410-004, Brasil. cvirgili@pop.com.br
}

\begin{abstract}
The relationship between female gender and mental illness is complex, remaining largely a product of women's social situation as daughters, wives, and mothers. The main objective of this article is to discuss the historical aspects related to mental illness in women in Porto Alegre, Rio Grande do Sul, Brazil, from 1870 to 1910. The authors consulted records from several so-called insane asylums as well as periodical articles published during the period. These documents provide good insight into how psychiatrists and lay society interpreted mental disorders in women. The research contributes to an understanding of the historical issues related to diagnosis of mental illness and the implications for current practice.
\end{abstract}

Mental Health; Women's Health; History of Medicine
Cristiane Teresinha de Deus Virgili Vasconcellos 1,2 Silvio José Lemos Vasconcellos 3,4

\section{Introdução}

Este artigo procura descrever como as mulheres consideradas loucas eram identificadas e tratadas no período de 1870 até 1910 , na cidade de Porto Alegre, Rio Grande do Sul, Brasil, bem como apresentar os fatores considerados desencadeantes desse quadro. $\mathrm{O}$ estudo mostra-se relevante pelo fato de não haver, em termos históricos, uma quantidade significativa de pesquisas contemplando esse assunto na cidade de Porto Alegre, no momento histórico aludido, existindo ainda uma notória escassez de fontes que ofereçam uma descrição mais ampla relacionada ao tópico. Acreditamos, também, que esta pesquisa possui caráter importante para a compreensão do assunto, que, por sua vez, não só beneficiará o estudo do passado, mas também promoverá uma melhor análise do presente em relação à mulher portadora de sofrimento psíquico e à forma como nós a enxergamos hoje. O trabalho irá contribuir, desse modo, para as disciplinas ligadas à saúde pública e à problemática em questão.

As fontes primárias utilizadas para esta pesquisa foram a imprensa escrita do período, os relatórios da Santa Casa, os processos-crime e as papeletas do Hospício São Pedro (o atual nome da instituição é Hospital Psiquiátrico São Pedro, portanto, quando nos referirmos à instituição no presente, é esse o nome que será utilizado; quando a referência for no momento histórico pesquisado, será chamado de Hospício São 
Pedro, pois foi esse o nome recebido em 1884, ano de sua fundação). Conforme destaca Hischumüller 1, em diferentes contextos, observa-se uma maior dificuldade em efetuar estudos de caso com base nessas mesmas fontes. Não podemos deixar de considerar que essas fontes primárias são instrumentos utilizados prioritariamente pelo discurso masculino vigente na época. Sabemos que cada jornal possuía uma vertente política ideológica, mas não nos detivemos nesse fato, já explorado por outros autores, como Petersem 2, o qual demonstrou, por intermédio de sua pesquisa, que mesmo os jornais socialistas divulgavam uma imagem da mulher semelhante à divulgada pelos demais jornais. Resultado com o qual concordamos, pois, nos mais diversos periódicos, encontramos a mesma visão a respeito da mulher, mesmo quando se tentava, de certa forma, encobrir essa posição. A imprensa propagou idéias, emitiu opiniões e, em virtude da forma como retrava "a mulher louca", criou uma imagem para esta.

Salienta-se que a pesquisa nos prontuários médicos (papeletas) foi precedida de uma autorização formalizada pelo Comitê de Ética em Pesquisa do Hospital Psiquiátrico São Pedro a partir do protocolo no. 00.005, estando adequada, ética e metodologicamente, às Diretrizes e Normas Regulamentadoras de Pesquisa Envolvendo Seres Humanos (Resolução no. 196/96 do Conselho Nacional de Saúde) e às Resoluções Normativas do Comitê em Ética em Pesquisa do Hospital Psiquiátrico São Pedro. Por motivos éticos, buscamos preservar o anonimato dos pacientes, colocando somente as iniciais dos seus nomes, incluindo os já relatados em publicações. Procuramos preservar, na transcrição das fontes primárias, a ortografia do período e os erros de impressão ou ortográficos, em face da importância relativa à precisão dessas fontes, pois traduzem a forma de expressão de uma época e de um lugar.

A coleta nas fontes primárias foi iniciada pelos jornais em 1999, buscando-se, num primeiro momento, todas as pautas referentes ao assunto. No ano de 2000, foram pesquisadas sete caixas contendo papeletas e documentos referentes aos pacientes internados no Hospício São Pedro entre 1884-1910. Tais caixas não estavam completamente organizadas em relação às datas; nelas, encontraram-se poucos dados sobre os pacientes e, na maioria das vezes, não existia uma explicação para a internação. Por sua vez, encontrou-se, nos jornais, a justificativa da internação de vários indivíduos e, quando havia relato de crimes, procedeu-se a uma coleta adicional nos processos-crime. Em relação à análise, buscouse averiguar a procedência e o nível social e econômico das mulheres citadas, realizando-se uma comparação com a situação histórica da cidade de Porto Alegre naquele período, bem como uma pesquisa sobre os diagnósticos encontrados nas fontes primárias, levando-se em consideração o que eles significavam e a qual alienista estavam ligados.

Desse modo, analisamos um conjunto de vários olhares sobre a mulher tida como louca. $\mathrm{O}$ primeiro refere-se à comunidade e à família a que pertencia, as quais, diante da percepção da alienação dessa mulher, pedem a sua internação. Esses dados foram obtidos por intermédio das cartas contidas em algumas papeletas. Um segundo olhar refere-se ao jornal que relata o ato de "loucura" por ela cometido ou simplesmente descreve a sua chegada à cidade. Por último, o olhar do médico, que verifica se ela realmente sofre de alienação mental, fornecendo o diagnóstico e o tratamento.

Esta pesquisa está ligada ao cotidiano, aos jornais, ao assunto loucura e mulher, temas antes considerados marginais na história, mas hoje já tendo décadas de pesquisa em diferentes vertentes teóricas. Acreditamos que a história cultural é a que nos possibilita maior liberdade de ação em relação às fronteiras. Em outras palavras, realizamos uma pesquisa histórica, mas dialogamos com a Antropologia, com diferentes ciências voltadas para o psiquismo humano e com as demais áreas afins. Conforme Chartier 3 (p. 16-7): “A história cultural, tal como a entendemos, tem por principal objecto identificar o modo como em diferentes lugares e momentos uma determinada realidade social é construída, pensada, dada a ler".

O marco temporal foi escolhido por acreditarmos que esses quarenta anos foram a primeira fase da "consolidação" de um saber especializado sobre a loucura nessa cidade. Os pedidos para a construção do hospício, a inauguração, a abolição da escravatura em 1884 mediante a prestação de serviços, a transição da monarquia para a república, a Revolução Federalista no Rio Grande do Sul (1893-1895), a fundação da Faculdade de Medicina em 1898 (nessa capital) e a formatura de sua primeira turma em 1904. Nessa virada de século, Porto Alegre é revitalizada, recebendo os ares da modernidade 4 . O limite é 1910, ano em que as irmãs da Congregação de São José iniciaram suas atividades relacionadas ao cuidado das pacientes. Acreditamos ser essa uma nova fase, visto que a responsável, Madre Fraçois de Sales, vinda da França, havia recebido a formação de enfermeira no Hospital de Bourg-Saint-Maurice, aperfeiçoando-se em Bourg-em-Bresse, local em que adquiriu conhecimentos especiais para o cuidado de alienados (Necrológios das Irmãs da Congregação de São José; s.d.). 


\section{Aspectos históricos do tratamento da doença mental em Porto Alegre no período que precedeu a construção do Hospício São Pedro}

Quando se pretende estudar sobre o tema loucura, é fundamental a leitura do livro História da Loucura na Idade Clássica, de Foucault 5, uma vez que se trata de um marco para a compreensão desse tema, fazendo-nos refletir e modificar o próprio enfrentamento sobre o assunto, que até então era tido como "tabu". Para o citado autor, cada época possui uma forma "estruturada de experiência” que comanda a ordem tanto dos discursos, quanto das práticas, além da própria ordem institucional. De acordo com Foucault 5, para Descartes o louco está impossibilitado de exercer a capacidade de pensar, justamente por causa da sua insanidade mental, ou seja, é o momento em que a razão exclui a loucura, e esse gesto é simultâneo ao confinamento dos loucos. Assim, o corte entre a razão e a desrazão é apenas uma expressão institucional do que está ocorrendo. A história da irracionalidade deve estar dentro das mesmas fronteiras que a história da razão, pois são cúmplices. Para Foucault, a Psiquiatria é apenas o monólogo da razão sobre a loucura e, em sua referida obra, realizou uma arqueologia do silêncio que foi imposto à segunda. Quando Pinel, em seu ato lendário, liberta os insanos das correntes, é pelo fato de que agora, através de uma organizada nosologia, elas não serão mais necessárias, pois as palavras passam a permitir um outro tipo de aprisionamento 5 .

O tratamento da doença mental sempre abarcou inúmeras particularidades e súbitas mudanças vinculadas a questões de época e lugar. Antes da fundação do Hospício São Pedro, os indivíduos considerados doentes mentais eram recolhidos à Santa Casa de Misericórdia, bem como à cadeia pública. Conforme assinala Piccininni 6 (p. 96): "Os doentes mentais eram recolhidos às prisões, mantidos em cárcere privado no fundo das fazendas ou recolhidos pela caridade pública aos porões da Santa Casa de Misericórdia".

No que se refere às condições em que os pacientes eram mantidos na Santa Casa, revela-se ilustrativa uma leitura de um relatório (Relatório do provedor da Santa Casa de Misericórdia da capital da Província do Rio Grande do Sul: José Antonio Coelho Junior. Porto Alegre: Arquivo Histórico da Santa Casa de Misericórdia de Porto Alegre; 1873), no qual constam afirmações de que, no passado, o número de alienados na Santa Casa era insignificante, mas que havia crescido muito num período recente. Destaca-se também, nesse mesmo relatório, a afirmação de que não era pequena a despesa para manter e reparar os estragos causados por tais internos. O "asylo de alienados da Santa Casa" é assim descrito no relatório de 1873 (p. 10): “Os pavimentos baixos deste edifício, únicos em que se póde collocar os loucos mais furiosos, são xadrezes escuros, frios e humidos, são verdadeiras masmorras, mais próprias por certo para fazer perder o juízo a quem o tiver do que para nellas recuperal".

"Ao ver-se esses infelizes sepultados nessas humildes e sombrias enxovias parece que a sociedade não quer cural os mem mesmo atenuar-lhes os seus soffrimentos, e sim que considera um crime a sua desgraça e que os quer punir com isso" (Relatório de 1873; p. 10).

Um caso que corrobora a afirmação de Piccininni 6 e a respectiva alusão ao fato de que os doentes eram mantidos em cárcere privado encontra-se no Processo Crime no. 2.789 de B. P. de Q. de 1874. Há, no citado documento, um relato explícito quanto ao fato de que a mulher em questão havia fugido da reclusão, quando assassinou um escravo. Não podendo ser considerada criminosa, o ato foi tido como improcedente. Assim, o promotor público escreve: “... advertindo mais, que no caso de ter de conservar-se a alienada em poder da familia, que se tomem as cautelas necessarias, afim de evitar a repercução de fatos idênticos" (Processo Crime no. 2.789; p. 33).

Constam, nesse mesmo processo, alguns testemunhos proferidos por diferentes indivíduos, nos quais se afirma que a mulher sofria das faculdades mentais, estando reclusa em um quarto, conforme se pode ler na seqüência: "B. P. de Q., que disem soffrer de alienação mental, evadiu-se da prisão em que se achava, fasendo grande barulho; e conseguindo perpetrou um assassinato na pessoa de M., escravo de C." (Processo Crime no. 2.789; p. 2).

“... a morte do dito escravo foi commettida em um accesso de loucura, depois de arrombar a prissão que se achava" (Processo Crime no. 2.789; p. 47).

Observa-se que a loucura era visualizada por leigos e aceita como um olhar legítimo pelas autoridades. Tal postura irá, então, mudar gradualmente, até a chegada de um período no qual apenas um saber especializado é capaz decifrála. No entanto, esse caminho mostrou-se longo, especificamente no Rio Grande do Sul, local onde a medicina consolidou-se apenas na década de 19407.

De acordo com o provedor da época, não existiam, entretanto, condições de tratamento para pessoas que perderam a razão. Em piores condições, estavam os alienados que eram enviados à cadeia.

"Que tratamento podem ter na cadêa civil esses desventurados, que não seja ainda peior do 
que o que podem ter neste estabelecimento?! E há de continuar uma sociedade chistã e civilizada, a collocar aquelles que perderam a razão, muitas vezes por injustiças da própria sociedade, nas mesmas condições em que colloca o malvado e o criminoso" (Relatório de 1873; p. 6).

Em 1874, mais uma vez, o provedor salienta a importância de um asilo de alienados. Relata a existência de alienados vagando soltos na sociedade e que " a imprensa de quando em quando registra crimes horriveis por elles praticados" (Relatório do provedor da Santa Casa de Misericórdia da capital da Província do Rio Grande do Sul: José Antonio Coelho Junior. Porto Alegre: Santa Casa de Misericórdia de Porto Alegre, 1874; p. 10); em adição, em casas de particulares, há outros que "ao menor descuido causão grandes desgraças" (Relatório de 1874; p. 10).

\section{O Hospício São Pedro}

O Hospício São Pedro, mesmo não estando totalmente construído, foi inaugurado com solenidade no dia 29 de junho de 1884, sendo transferidos para lá 14 homens e 11 mulheres da Santa Casa e 10 homens e 6 mulheres provenientes da cadeia pública.

No relatório de 1884 do Dr. Carlos Lisbôa (Relatório do Hospício São Pedro apresentado ao Exmo. Sr. Coronel Joaquim Pedro Salgado, provedor da Santa Casa de Misericórdia de Porto Alegre. Porto Alegre: Arquivo Histórico da Santa Casa de Misericórdia de Porto Alegre, 1884), constam referências ao fato de ainda não haver, nesse período, uma farmácia, bem como de existir um limitado número de drogas. Por outro lado, a respeito do tratamento moral apregoado na época, Dr. Lisbôa lamentava não poder utilizá-lo com todos os requisitos, tendo em vista que faltavam recursos para tanto. Destaca-se o fato de o citado diretor ressaltar a existência de duas teorias sobre a loucura, uma que a considerava como um fato de ordem puramente física, cujo tratamento deveria ser estritamente físico, e outra que afirmava ser a loucura uma perturbação psicológica, e só o tratamento moral seria satisfatório. Lisbôa acreditava que a mera utilização de uma sem a outra nada produziria para a melhora do alienado; esta só poderia ocorrer com a combinação de ambas. A prática desse ecletismo dura trinta anos no Hospício São Pedro, apesar do precoce falecimento do médico.

No mesmo relatório, Lisbôa relata existir uma proporcionalidade no que diz respeito ao número de mulheres e homens e, justamente por isso, queixa-se, pois, de acordo com o seu entendimento, em termos de especificidade do trata- mento, era fato sabido que as mulheres alienadas davam muito mais trabalho que os homens. Apesar disso, porém, quem fez o regulamento do Hospício São Pedro criou dois lugares para enfermeiros e apenas um para enfermeira, sendo esta menos remunerada que os homens. Observamos, dessa forma, que a visão sobre a loucura feminina diferenciava-se daquela que recaía sobre a masculina, considerando-se, ainda, que a doente dava maior trabalho e que a enfermeira, isto é, a mulher sadia que tinha o dever de cuidar da paciente, trabalhava por um valor inferior ao valor comumente pago aos homens.

Salienta-se que o século XIX é conhecido como o século dos manicômios, pois nele se multiplicaram as teorias a respeito da loucura e a construção de locais específicos para o tratamento da doença. Foi, portanto, no manicômio que surgiu a psiquiatria como especialidade médica.

\section{Motivos que a sociedade julgava serem suficientes para uma mulher enlouquecer}

Como bem destaca Canguilhem 8, o comportamento considerado normal pode variar significativamente no tempo e no espaço, ou seja, é um processo histórico que se modifica de cultura para cultura. Dessa forma, os motivos que supostamente explicam o enlouquecimento de uma mulher também variam para a sociedade em diferentes épocas. Nesse sentido, descreveremos não o comportamento anormal, mas as razões que supostamente sustentaram tal concepção. Se para muitas "loucuras" não se encontram os motivos, exatamente pelo fato de serem "loucuras”, para outras, eles estão presentes. Certas mulheres poderiam ter a sua "loucura" desencadeada por uma dor moral muito forte, uma doença orgânica, ou por qualquer outra causa. Assim, tendo por base uma análise mais detalhada das papeletas do Hospício São Pedro (Arquivo Público do Rio Grande do Sul, caixas 1-7; 1884-1910) e dos jornais da época, o presente artigo passará a explicitar alguns casos elucidativos no que diz respeito aos motivos que eram, no período em estudo, concebidos como desencadeantes da própria alienação.

Rohden ${ }^{9}$ escreve que a mulher era vista como um ser sempre ligado a sua função reprodutora, e as fases de sua vida, como puberdade, gravidez e menopausa, podiam ser desencadeantes de desequilíbrios emocionais. Dessa forma, durante toda a vida, a mulher seria um ser propício a perturbações mentais, e a menstruação estava em destaque nas discussões a respeito desse problema. Marland 10 destaca, além disso, a relação das próprias doenças que supostamente atingiriam o 
psiquismo feminino com o ciclo reprodutivo em seus diferentes aspectos.

Nas referidas papeletas, é possível encontrar: “M. dos S. L., no 2945, 24 anos, casada com M. A. de R., brasileira. Admitida provisoriamente em 05/02/1909 e definitivamente em 20/02/1909. Adoeceu 15 dias depois do parto. Diagnóstico: 'Loucura post-partum-depressão melancólica delirante.' 'Impressões suicidas levadas pelas idéias delirantes.' Saiu curada do acesso em 17/06/1910”.

“L. M. J., no 3021, 17 anos, casada, branca, brasileira, admitida provisoriamente em 10/08/1909 e definitivamente em 25/08/1909. Diagnóstico de confusão mental. Saiu curada em 06/01/1910".

“Atestamos que D. L.M.J.com 17 anos de idade, branca, casada, acha-se soffrendo de uma pychose consecutiva a um estado puerperal, necessita, por isso, ser internada no Hospício S. Pedro, afim de ser convinientemente observada e tratada. Porto Alegre, 09 de agosto de 1909. Dr. J.".

“A. F, no 1761, 20 anos, diagnóstico de mania aguda, entrou em 23.03.1901 e saiu curada em 24.04.1902 e seguiu para Pelotas a pedido de seus familiares. Deu à luz uma criança do sexo feminino no dia 23.04.1901 que foi levada para a Roda do Expostos da Santa Casa de Misericórdia de Porto Alegre".

Conjeturamos, pois não temos dados para uma análise conclusiva, que talvez algumas mulheres possam ter sido internadas para darem à luz longe da sociedade, como podemos observar em "M. K., no 2245, 18 anos, solteira, que entrou em 25.08.1904 e saiu curada em 25.05.1905” (Papeletas do Hospício São Pedro). No dia 29 de março de 1905, é anotado que ela chegou ao hospício grávida e pariu um menino de parto normal. Ou seja, ela "enlouqueceu" ao engravidar e curou-se logo após ter a criança. Seu diagnóstico era de excitação maníaca.

"S. B. 1.183, vide 494, com 25 anos, solteira, parda, brasileira. Foi admitida em 15/07/1897 e teve alta em 15/09/1898. Seu diagnóstico era de "excitação maníaca remittente". Alta curada em 15/09/1898. Observação: a doente a quem se refere esta papeleta já esteve neste estabelecimento sofrendo também de excitação maníaca, q. foi gradativamente cedendo, a proporção q. progredia a gestação, sob cuja influencia apareceu a moléstia mental que a trouce a este Hospicio, donde afinal sahiu curada em 21 set de 1890, tendo dado entrada em 11 de junho do mesmo ano (Dr. T. T.)" (Papeletas do Hospício São Pedro).

“L. M. B. casada com A. B., branca, brasileira, profissão serviços domésticos, admissão definitiva em 26/02/1901 teve alta melhorada a pedido do marido em 08/08/1901" (Papeletas do Hospício São Pedro). Seu diagnóstico era de mania aguda e erotismo. Mas, em 19 de março de 1903, é in- ternada novamente com o mesmo diagnóstico, vindo a falecer em 20 de janeiro de 1948. Seus diagnósticos, no tempo em que esteve internada, foram de mania aguda, mania crônica, erotismo e demência senil.

Rohden ${ }^{9}$ relata o caso Abel Parente, médico italiano que clinicou no Rio de Janeiro no final do século XIX e início do XX. Médico "de senhoras", realizava em suas pacientes uma técnica para impedir a concepção e foi acusado de esterilizador e responsável pelo enlouquecimento de sua paciente M. A. de F. do B.

"Afirmam, parentes e amigos que, algum tempo depois das primeiras intervenções, começou a paciente a apresentar modificação de caráter, tornando-se tristonha e concentrada, de jovial que antes era. Este estado de espírito foi cada vez mais se acentuando, de tal forma que, em princípios do mês de novembro, apresentou-se em franco estado melancólico. No dia anterior ao da conferência teve violenta crise de agitação, acompanhada de delírios eróticos, manifestando atitudes obscenas e usando de linguagem incompatível com a sua educação" 9 (p. 180).

Rohden ${ }^{9}$ observa que a falta de razão de M. A. de F. do B. era evidenciada pela recusa em obedecer ao marido e por expressar desejos eróticos, e que isso só poderia ter ocorrido (conforme acreditavam alguns médicos do período) em virtude das intervenções externas, no caso, a supressão brusca das regras provocada pelo procedimento médico. A autora também salienta que, quando uma mulher realizava um comportamento antisocial, ela não era acusada e, sim, definida como uma vítima ou uma doente, o que retirava dela o poder de demonstrar suas insatisfações em relação à situação que vivia. Rago 11 lembra que, para Lombroso, a prostituta é uma "louca moral"; logo, a mulher normal é aquela com instintos maternais e deserotizada. Foucault 12 afirma que, no século XIX, desenvolve-se um saber a respeito da sexualidade. Dessa forma, a sexualidade permitida é aquela concebida como saudável, higiênica, realizada no casamento, entre quatro paredes e com fins reprodutivos. Em oposição, apresentase outra, que é danosa, ilícita e perigosa para a saúde, quer física ou mental. Nesse sentido, a mulher normal é a esposa e mãe; opondo-se a ela, está a prostituta. Essa mulher normal tem seu corpo voltado inteiramente para as funções reprodutoras, sendo esse corpo perturbado por essas mesmas funções 12 .

O sofrimento também era uma razão que poderia levar à loucura. Numa das papeletas, encontramos a paciente “M. C. S., Classe: 3o, no 1083, internada em: 21/11/1896, tendo em 5/12/1896 alta a pedido". Tinha cinqüenta anos, era casada e de nacionalidade italiana. A requisição para sua 
internação foi emitida pelo desembargador chefe de polícia. O diagnóstico foi de "lypemania" e, embora não tenha sido possível encontrar o motivo de sua loucura e nenhuma descrição histórica relativa a sua doença, no livro de Correa ${ }^{13}$, verificamos que o motivo para o seu enlouquecimento era o estupro de uma filha, cometido por um padre. Tais considerações baseiam-se no que os jornais evidenciam por intermédio dos artigos transcritos. Alude-se a um motivo justificável, uma vez que o crime cometido por um padre abala a estrutura familiar, e uma mãe zelosa não consegue suportar. Entendemos que o enlouquecimento dessa mulher enfatiza a crueldade cometida, permitindo uma maior culpabilidade não só pelo ato, mas por toda a conseqüência gerada. Dessa forma, não só o anticlericalismo apontado por Correa 13 é manifestado, como também a loucura feminina ganha visibilidade. O ponto para o qual chamamos atenção refere-se ao fato de que tal crime enlouquece uma mulher, ou seja, a mãe. O pai, de outro modo, não enlouquece; é tão-somente desonrado. A mulher é concebida como frágil, e a sua natureza é afetiva e passiva. De acordo com tal concepção, não se estranha que a dor do acontecido a desestruture. Acrescentamos, também, o fato de que ela, como mãe, é vista como a responsável pela preservação da virgindade de sua filha. Apesar de o jornal Correio do Povo (1896; 27 set: p. 1) noticiar que o exame médico legal não constatou seu "defloramento", consta em suas páginas que "embora virgem, embora pura, embora innocente, quem ahi a quereria para esposa?".

Segundo Correa 13, no jornal A Gazetinha de 25 de julho de 1896, consta a denúncia de um estupro cometido por um padre contra uma menina de 11 anos, C. S. Em 11 de outubro de 1896, é publicado nesse periódico: "É em nome da moral social, senhores da justiça - toda a inexorabilidade na punição do miserável roupeta que estuprou a pobrezinha C. S. A perdição de uma criança, a loucura de uma desgraçada mãe, o súplicio avérnico da desonra de um pai, o infortúnio de uma família, tudo isso afinal deve mover a inclemência da justiça contra quem o causou" 13 (p. 56).

No dia 26 de novembro 1896, no mesmo jornal (A Gazetinha), temos o artigo A Louca: "Quando crente de que estava preparando uma esposa digna de qualquer homem honrado e escrupuloso em pontos de moralidade, se lhe destrói essa esperança tão razoável, tão simples e tão natural. (...) A desonra de uma criança $e$ quiçá o nome de uma família inteira, a loucura da progenitora daquela, eis o que foi o resultado da entrega de uma consciência infantil, por meio dos embustes das sacristias, a um Dom Juam de Batina" 13 (p. 55).
Em 1896, o jornal Correio do Povo (1896; 24 set; p. 2) noticia que: "Diz-se que enlouqueceu a italiana M. C. S., mãe da menor C., protagonista do caso das Dores. M. C. reside á rua Riachuelo no 178, e consta que terça-feira será recolhida ao hospício S. Pedro". No Arquivo Histórico do Rio Grande do Sul, encontram-se mais detalhes sobre o crime (Códices da Polícia, livro 04; p. 51.).

Observando que existiam padrões para o comportamento feminino e para o masculino, constata-se que o que pode causar o desequilíbrio mental de um não é necessariamente o que vai causar o do outro. A mulher estava circunscrita ao lar, ao marido e aos filhos; já o homem deveria sustentar essa família. Isso não significa que era o que de fato ocorria, mas sim que era um padrão de comportamento esperado, pois observamos que as mulheres 14 das classes populares assumiam o papel de provedoras de seu grupo, realizando, dessa forma, papéis que eram masculinos. Mas, se, nas classes populares, isso era compreendido, o mesmo não ocorria com as mais abastadas, que recebiam uma instrução adequada para o seu papel de esposa e de mãe educadora dos filhos, mas como alguém que não deveria trilhar os caminhos intelectuais devido ao seu frágil cérebro que acabaria por sofrer graves perturbações mentais.

Um bom exemplo, nesse sentido, diz respeito aos jornais da época, nos quais se podem encontrar determinadas características e qualidades relativas ao que era esperado de uma mulher. Para um homem, a ruína nos negócios era um motivo justificado para o seu enlouquecimento, uma vez que ele era visto como o pai de família, o provedor responsável pelo meio externo. No que se refere à mulher, entretanto, a loucura é justificada pela dor de perder um filho, já que ser mãe era o fim último de uma mulher.

Dessa forma, a causa da loucura aludida no jornal cuja transcrição é apresentada na seqüência encontra legitimidade com base nos papéis atribuídos aos sexos. Embora os casos narrados não tivessem acontecido em Porto Alegre, os jornais que os noticiaram eram dessa cidade, exercendo, assim, influência na forma como era concebida a insanidade nesse contexto. No Jornal Mercantil (1884; 4 ago; p. 2), lemos o artigo "Louca de dor. O tristissimo caso que segue ocorreu em Buenos Aires. M. T. C. é uma pobre jovem italiana, de 28 annos de idade, que há poucos mezes ficou viúva, sendo mãe de dous meninos, um de 10 annos de idade e outro de um ...". O menino de dez anos adoeceu e acabou por falecer no hospital: "O enfermeiro lhe respondeu seccamente: 'o ocupante d'este numero falleceu esta noite'. A pobre mãi não disse uma palavra: estreitou convulsivamente o outro filho que levava nos braços, 
passou um olhar desvairado pela sala e deu uma sonora gargalhada. Estava louca! Innuteis foram os promptos auxílios que lhe prestou o medico de serviço no hospital. T. passou successivamente do riso ao desespero e d'este á manifestação da mais acerba dor: arrancava os cabellos e intentava bater a cabeça contra as paredes. Com muito custo se pôde tirar o menino que tinha nos braços, do qual apertava com tal força que por pouco o afogou. A policia, como era de seu dever, interveio n'este lamentável incidente, tomando a si a louca, em quem devia affectuar-se o reconhecimento medico legal de pratica, e procedeu á indagação do ocorrido. A policia, também chamou o menino que a pobre mãi trazia nos braços no momento de perder a razão em occasião de supremo desespero".

Dezesseis dias após essa noticia, na mesma imprensa escrita, outro relato sobre um "enlouquecimento", dessa vez o de um homem. Infere-se que a manifestação da doença mental era algo que devia ser transmitido aos leitores, afinal o Hospício São Pedro havia sido inaugurado há menos de um mês e era importante que percebessem o quando essa doença estava presente.

"Louco por quebrar. Constava na corte, por telegramma recebido de S. Paulo, que enlouquecera em Santos, o negociante S. Q., sócio da importante casa daquella praça S. Q. e V. informaram de que esse desastre fora devido a transacções de café, em que elle tivera prejuízo calculado em 1,600 contos" (Jornal Mercantil 1884; 20 ago; p. 2).

\section{Motivos que justificavam a internação}

Quando a sociedade não encontra referencial simbólico que justifique a atitude de um de seus membros e este não consegue manter-se dentro dos padrões de normalidade de sua comunidade, esta tende a vê-lo como alienado. Quando alguém sai do padrão estabelecido e realiza atitudes descabidas, tornando-se incapaz de ser normativo, pode verdadeiramente ser definido como louco: "Una definición perfectamente correcta de uma persona loca es que ésta se conduzca de uma forma no predecible, dejendo de hacer lo que la sociedade espera de ella" 15 (p. 67).

Nesses termos, constata-se que a internação normalmente era realizada a pedido da própria família ou da comunidade que, observando o desajustamento social de um individuo, pedia a internação deste a uma autoridade competente. Observa-se, também, que a necessidade de isolamento, tal como é possível ler nos seguintes casos, era uma das justificativas para esse ato: "attesto que D. G. B. P. de cor branca, solteira, de vinte e quatro anos de idade, natural deste estado e residente nesta cidade sofre de loucura periódica, de fundo hysterico, de forma (...), com intervalos lúcidos de duração variável, apresentando recrudescencias bruscas e transitorias, nestes intervalos, o que é comum a esta forma de loucura. Julgamos assim de imprecindivel necessidade a internação desta senhora no hospício de Porto Alegre, pois que só o isolamento completo ou relativo, lhe poderá proporcionar restabelecimento completo ou relativo, das faculdades mentais. Bagé 14 de janeiro de 1909. (R. V.S. Doutor em ciências medico cirúrgico pela faculdade do Rio de Janeiro)" (Papeletas do Hospício São Pedro). Observação: Essa paciente foi internada 12 vezes, de 1909 até 1946. Seu primeiro diagnóstico foi de "loucura hysterica" e o último de "psicose maníaco-depressiva".

"Attesto que a Srt.a M. da G. M. B., branca, solteira, 28 annos de idade, natural desta capital, profissão domestica, residente á rua Demetrio Ribeiro no 57, está soffrendo de moléstia mental pela qual necessita isolamento e tratamento em estabelecimento especial. Chefatura de polícia. Dr. C. P. 20/11/1907. Obs. Diagnóstico 'loucura hysterica', saiu curada em 16/03/1908" (Papeletas do Hospício São Pedro).

No século XIX, segundo Foucault 12, acontece a histerização da mulher, pois ela estava ligada ao seu corpo de uma forma diferente do homem, estava presa a sua condição reprodutora. Salienta Venâncio 16 (p. 296): "O corpo feminino aparecia como mais permeável à histeria do que o organismo masculino, considerando-se inclusive sua maior predisposição em fases específicas como puberdade, gravidez e menopausa".

Foucault 17 lembra, ainda, que Esquirol postulava que os loucos deveriam ficar isolados, já que somente dessa forma seria possível a realização de um tratamento adequado. Suas justificativas baseiam-se principalmente em: viabilizar a segurança do doente e de sua família; libertá-lo de influências externas; vencer as resistências pessoais do insano; submetê-lo à força a um regime médico; impor-lhe novos hábitos morais e intelectuais.

“Certificado medico: Eu abaixo assignado Medico Cirúrgico formado pela Faculdade de Pádua (Itália) attesto que a Colona O. F. de 29 annos de idade esta affecta de mania de perseguição em alto grau, accompanhada com allucinações mentaes de forma delirantes. A dita demente torna-se incompativel de conviver na sociedade, é por isto de imprescindivel necessidade recolhe-la em um hospício. Dr. O. P. Medico Cirúrgico 04/07/1909" (Papeletas do Hospício São Pedro).

A agressão que algumas alienadas realizavam também era um fator relevante para o pedido de seu tratamento.

“A. dos S. P., 41 anos, portuguesa, casada, branca desta capital, admitida em 30/01/1891 
teve alta para assistência em 31/12/1914. Muitas vezes furiosa atira-se contra aos propris filhinhos com ímpetos de estrangulal-os outra offende a moral publica" (Papeletas do Hospício São Pedro).

“L. P., 35 anos, admitida provisoriamente em 13/08/1908 e definitivamente em 28/08/1908, diagnóstico: 'demencia paranoide. Idéias mysticas', tendo alta por falecimento devido a 'caquexia por enterite chonica' em 04/10/29" (Papeletas do Hospício São Pedro).

Em carta para o diretor do Hospício São Pedro, o intendente municipal de Alfredo Chaves escreve: "segue para ser internada no Hospício São Pedro em Porto alegre, por conta desta intendencia, a alienada L. P., filha de R. P., com trinta e seis annos de idade, residente nesta villa de Alfredo Chaves, natural da Itália, branca, casada (abandonada pelo marido) profissão serviços domésticos. Motivo sua reclusão no hospício repetidas tentativas de incêndio e espanacamento de crianças encontra à rua" (Papeletas do Hospício São Pedro).

No jornal A Federação (1896; 23 mar; p. 2), lemos: "Foi presa B. A., em flagrante, quando, armada de uma faca na Igreja dos Passos, produzindo grande alarido entre o povo que la estava, e ter ferido levemente uma preta já idosa, de nome J. da C.. Segundo informações que temos B. A. sofre de alienação mental".

No Hospício São Pedro, encontramos relatos sobre uma paciente com o mesmo nome (provavelmente a mesma referida no jornal) que foi internada no dia 2 de abril de 1896; tinha quarenta anos presumíveis, era solteira, $4 \underline{\text { a }}$ classe, ou seja pobre. Seu diagnóstico foi de megalomania e faleceu no mesmo ano, no dia 22 de julho, de tuberculose pulmonar. $\mathrm{O}$ requerimento para internação, como podemos ler, era da chefatura de polícia: "Cheffatura de Policia 27 de março de
1896: Acha-se soffrendo das faculdades mentais a mulher B. A., que se acha recolhida à casa de correção desta Capital, solicito-vos a sua admissão nesse estabalecimento" (Papeletas do Hospício São Pedro).

\section{Conclusão}

Procuramos mostrar, por intermédio principalmente de fontes primárias, a forma como a loucura feminina era descrita e ganhava visibilidade nesse contexto. De modo geral, esta pesquisa evidenciou uma forma distinta de enxergar a mulher considerada "louca" no período estudado, na cidade de Porto Alegre, e, ao mesmo tempo, uma forma condizente com uma série de concepções da época. Este estudo necessita de uma continuidade, bem como de uma ampliação. Acreditamos que as fontes primárias são o melhor caminho para uma investigação desse tipo. Dentre elas, uma escolha que deve ser considerada é a busca pela produção médica da época, o que não foi contemplado em nossa pesquisa.

A loucura feminina foi "diagnosticada" tanto por leigos, como por especialistas, e, embora hoje possamos não concordar mais com tais classificações, esse "diagnóstico" mostra-nos um pouco dessa sociedade e a forma como ela manifestou-se diante de uma problemática específica. “A História deve buscar a compreensão de como as percepções acerca do estar no mundo mudaram e, para tanto, não tem como deixar de reconhecer que não trabalha com o estanque, pois remete-se exatamente ao mais dinâmico" 18 (p. 500). O olhar que a sociedade dirigia para a alienada mental era, portanto, condizente com o momento histórico, assim como o olhar que hoje lançamos para esses mesmos trabalhos demonstra ser concordante com nossas concepções presentes. 


\section{Resumo}

A relação entre mulher e loucura é complexa. Remetenos amplamente à situação social das mulheres como filhas, esposas e mães. O principal objetivo deste artigo é discutir os aspectos históricos relacionados à insanidade das mulheres na cidade de Porto Alegre, Rio Grande do Sul, Brasil (1870-1910). Os autores consultaram um grande número de registros hospitalares $e$ artigos de jornais publicados no período mencionado. Esses documentos fornecem uma boa compreensão da forma como os alienistas e membros da sociedade em geral interpretaram a doença mental nas mulheres. A pesquisa contribui para a compreensão da questão histórica relativa ao diagnóstico da doença mental, bem como de suas implicações para as práticas atuais.

Saúde Mental; Saúde da Mulher; História da Medicina

\section{Referências}

1. Hirschmüller A. The development of psychiatry and neurology in the nineteenth century. Hist Psychiatry 1999; 10 (40 Pt 4):395-423.

2. Petersem SRF. A mulher na imprensa operária gaúcha no século XIX. Rev Bras Hist 1886/1887; 1:83110.

3. Chartier R. A nova história cultural: entre práticas e representações. Lisboa: Difel/Rio de Janeiro: Beltrand; 1990.

4. Mauch C, Vargas AZ, Elmir CP, organizadores. Porto Alegre na virada do século 19: cultura e sociedade. Porto Alegre: Editora da Universidade Federal do Rio Grande do Sul/Canoas: Editora da Universidade Luterana do Brasil/São Leopoldo: Editora Unisinos; 1994.

5. Foucault M. História da loucura na idade clássica. São Paulo: Editora Perspectiva; 1997.

6. Piccinini WJ. Breve história da psiquiatria do Rio Grande do Sul à luz das suas publicações. Rev Psiquiatr Rio Gd Sul 1999; 21:95-103.

7. Weber BT. As artes de curar: medicina, religião, magia e positivismo na República Rio-Grandense - 1889/1928. Santa Maria: Editora da Universidade Federal de Santa Maria/Bauru: Editora da Universidade do Sagrado Coração; 1999.

8. Canghilhem G. O normal e o patológico. Rio de Janeiro: Editora Forense Universitária; 2002.

9. Rohden F. Uma ciência da diferença: sexo e gênero na medicina da mulher. Rio de Janeiro: Editora Fiocruz; 2001.

\section{Colaboradores}

C. T. D. V. Vasconcellos realizou a pesquisa nas fontes primárias e elaborou texto, assim como a pesquisa bibliográfica. S. J. L. Vasconcellos participou de uma parte da pesquisa bibliográfica, bem como da elaboração e revisão final do texto.
10. Marland H. Disappointment and desolation: women, doctors and interpretations of puerperal insanity in the nineteenth century. Hist Psychiatry 2003; 14:303-20.

11. Rago M. Os prazeres da noite: prostituição e códigos da sexualidade feminina em São Paulo (18801930). Rio de Janeiro: Editora Paz e Terra; 1991.

12. Foucault M. História da sexualidade: I. A vontade de saber. Rio de Janeiro: Edições Graal; 2005.

13. Correa SMS. Sexualidade e poder na Bélle Èpoque de Porto Alegre. Santa Cruz do Sul: Editora da Universidade de Santa Cruz do Sul; 1994.

14. Dias MOLS. Quotidiano e poder em São Paulo no século XIX. São Paulo: Editora Brasiliense; 1995.

15. Service ER. Los orígenes del Estado y de la civilización. Madrid: Alianza Editorial; 1984.

16. Venancio ATA. Doença mental, raça e sexualidade nas teorias psiquiátricas de Juliano Moreira. Physis (Rio J) 2004; 14:283-305.

17. Foucault M. Resumo dos cursos do Collège de France (1970-1982). Rio de Janeiro: Jorge Zahar Editor; 1997.

18. Cardoso MHCA, Gomes R. Representações sociais e história: referenciais teórico-metodológicos para o campo da saúde coletiva. Cad Saúde Pública 2000; 16:499-506.

Recebido em 16/Nov/2005

Versão final reapresentada em 16/Mai/2006 Aprovado em 20/Jun/2006 